\title{
Entrevista a Ricaurte Soler
}

\author{
Rodrigo Espino/Raúl Martínez
}

La historia panameña del siglo XIX se distingue por una serie de particularidades, de las que el Dr. Ricaurte Soler nos habla, de manera general, en la entrevista realizada el 30 de noviembre de 1984 en la ciudad de México.

Antes de entrar en materia, creemos pertinente anotar algunos datos acerca del entrevistado. Ricaurte Soler nació en La Concepción, Chiriquí (Panamá) en 1932. Obtuvo la licenciatura en Filosofía y Letras en la Universidad Nacional de Panamá. Realizó otros estudios en la Universidad Nacional Autónoma de México (UNAM), en 1959; en la Universidad de Vincennes (Francia), 1969-1970; en el Instituto de Altos Estudios de la América Latina (Paris), 19691970. Se doctoró en Filosofía en la Universidad de París (La Sorbona). Fue fundador y director de la Revista Tareas durante más de veinte años. Actualmente es director del Departamento de Historia de la Universidad de Panamá.

Los trabajos del doctor Soler ocupan un lugar destacado en la historiografia de Panamá; en ellos aborda distintos problemas del acontecer histórico del pais, especialmente el que se refiere a la nacionalidad.

$P$. Actualmente, en el Instituto José María Luis Mora realizamos una investigación sobre la historia de Panamá durante el siglo. XIX. A lo largo de nuestro acercamiento hemos notado la exclusión de Panamá en los estudios sobre América Central; por tal motivo nos gustaria saber su opinión sobre cuáles son las principales causas por las que se excluye a Panamá de los estudios históricos centroamericanos.

$R$. Sí. Hay una razón que nosotros los panameños respondemos un poco rápidamente, porque es muy clara: Panamá, históricamente, ha estado ligada a Sudamérica, ha estado ligada a Perú durante la época del transitismo,' en los siglos XVI, XVII, y a principios del XVIII: después estuvo ligada a la Nueva Granada, cuando se creó el Virreinato a finales de 1739,1740 , poco más o menos;

\footnotetext{
' El término "transitismo" define el carácter de la economía panameña sustentado en el paso de mercancías de un oceáno a otro. Desde el siglo XVI, la economia panameña tuvo como base principal el tráfico tanto de mercancías de España hacia Centro y Sudamérica, como de riquezas americanas hacia la península. El gran auge mercantil se puso de manifiesto con la realización periódica de ferias en Portobelo (población de la vertiente atlántica que estaba comunicada por tierra con la ciudad de Panamá, localizada en la costa del Pacífico), ferias que finalizaron alrededor de 1739. En esta fecha la ruta naviera se cambia al Cabo de Hornos, a causa del constante hostigamiento filibustero. Véase entre otros textos, el artículo de Alfredo Castillero Calvo, "Transitismo y dependencia: el caso del istmo de Panamá", en Loteria. Panamá, núm. 210, julio de 1973.
} 
la Nueva Granada es lo que hoy es Colombia. ${ }^{2}$ Bien, entonces esto es hasta la independencia de 1903. De manera que nosotros acostumbramos decir que geográficamente somos Centroamérica, pero históricamente estamos ligados más bien a Sudamérica. Claro, esto $\sin$ incluir las relaciones con el mercado mundial capitalista; ya esto implica entonces otras relaciones -como la relación con los Estados Unidos-, que para nosotros son absolutamente vitales; han sido, lo son y lo serán, con la construcción del ferrocarril de 1850-55, el canal francés en la década de los 80 , y después el canal norteamericano de 1904 a 1914; pero independientemente de los nexos con la economía capitalista mundial, los otros nexos que hemos tenido más bien han sido con Sudamérica y no con Centro-

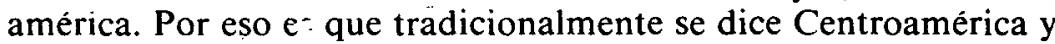
Panamá.

$P$. Según esto, ¿es pertinente tratar la historia de Panamá, a partir de fines del siglo XVIII y principios del XIX, en forma particular y distinta, con respecto a los paises centroamericanos y Colombia?

$R$. Yo respondería de la misma forma, respondería que sí. Ahora, y no sé si ustedes han leído el librito mio Formas ideologicas de la nación panameña... ${ }^{3}$ Hay también otro librito: Panamá en el mundo americano.... pero sobre todo en los últimos trabajos mios, trato de señalar algo que es muy característico de Panamá, por lo que se refiere al siglo XVIII, que es lo siguiente: en tanto que durante el siglo XVIII, y particularmente en su segunda mitad, nos encontramos con un crecimiento de las ciudades a escala de toda Hispanoamérica; crecen las ciudades... crece Buenos Aires, crece, qué sé yo, Montevideo, crecen las ciudades puerto en particular. Hay una relativa libertad de comercio con Carlos III. Entonces esto implica un crecimiento de las ciudades, un crecimiento urbanístico notable, y también un crecimiento demográfico importante. En tanto que todo esto es así a escala de América Hispana, en Panamá, durante el siglo xvill es exactamente al revés; como se cambia la ruta, entonces hay una profunda decadencia económica; las ciudades de Panamá y Portobelo se quedan convertidas en villorrios, sobre todo Portobelo, que queda convertida en villorrio después que desaparecen las ferias de Portobelo. ${ }^{5}$ Esto es muy importante, para mí es muy importante el siglo XviII panameño, ya que explica por qué los centros urbanos de Panamá no lograron darle un cierto espacio, espacio homogéneo, al istmo de Panamá,

- El Virreinato de Nueva Granada -también conocido como Santa Fe (nombre de la capital del Virreinato)- estuvo integrado por la capitanía de Venezuela, la presidencia de Quito (Ecuador), por la audiencia de tierra firme o Panamá y por el territorio que actualmente ocupa Colombia. Después de 1821 , estos territorios ya independientes adoptan el nombre de "Gran Colombia". Luego de 1830, Venezuela y Ecuador se separaron de la "Gran Colombia" y Panamá quedó incorporado a la entidad política denominada Nueva Granada con la que estableció una relación conflictiva durante sus distintas etapas políticas a lo largo del siglo XIX, hasta su separación definitiva en 1903.

? Publicado en San José, por EDUCA, en 1972.

4 Publicado en su Tercera edición en Panamá por la Librería Cultural Panameña, en 1975.

${ }^{5}$ Para mayor información sobre las ferias de Portobelo, véase Clarence $\mathrm{H}$. Haring. El comercio y la navegación entre España y las Indias en la época de los Habsburgos, Paris-Brujas, Desclée de Brouwer, 1939, especialmente las páginas 205-224. 
que pudiese permitirnos una independencia cuando se desmembró la Gran Colombia, Ecuador... Como ustedes ya saben, Ecuador forma un estado nacional aparte, Venezuela forma un estado nacional aparte y Nueva Granada un estado nacional aparte; sin embargo, Panamá no. $Y$ esto se debe en gran parte a la profunda decadencia económica de Panamá durante el siglo XVIII. Y con esto yo no quiero estar haciendo la apología de la desmembración, todo lo contrario, sino que dadas las características del imperio español era realmente un sueño aquello que pretendía Bolívar de la unidad hispanoamericana. La solidaridad hispanoamericana se dará en otros niveles, pero no precisamente en la forma... por lo menos como lo pensó Bolívar en un principio. En Panamá nosotros tenemos que nuestro principal teórico de la soberanía y de la autodeterminación es Justo Arosemena. Sin embargo, Justo Arosemena -y esto es algo que se olvida mucho-, también fue un propugnador de la unidad hispanoamericana con un libro suyo que se llama Estudios sobre una idea de una liga americana, ${ }^{6}$ que se publicó en 1864, y además con otros muchos artículos. De manera que este siglo xvill es muy importante. Hay que tener muy en consideración que hay ciertas especificidades para Panamá durante el siglo XVIII que son las que en cierta manera explican la formación tardia del estado nacional panameño.

$P$. ¿Cuál es su opinión sobre la independencia de Panamá, de* España, en 1821 ?

$R$. Bueno, le dije hace poco que es muy importante el poder contestar esta pregunta. ¿Por qué Panamá no pudo formar un estado nacional aparte cuando se desmembró la Gran Colombia? Panamá se independiza de España de una manera autónoma; los ejércitos de Bolívar no tuvieron que ver nada con la independencia de Panamá, sino indirectamente. Evidentemente que la batalla de Boyacá de 1819 hizo posible la independencia de Panamá de 1821 , pero es una posibilidad indirecta, quiero decir, no fue realizada directamente por Bolivar la independencia de Panamá de España en 1821. Decimos nosotros tradicionalmente que fue una independencia espontánea, en el sentido de que los diferentes municipios, ciudades, etcétera, se declaran independientes a partir sobre todo de la independencia del 28 de noviembre, declarada en la ciudad de Panamá. Esto es algo en lo que yo he insistido mucho, la importancia del artículo noveno del acta de independencia de 1821 , porque ese articulo noveno dice que Panamá formará los reglamentos económicos convenientes para su gobierno interior, lo cual está implicando que Panamá está reivindicando la autonomía económica en los momentos mismos en que está anexándose a la Gran Colombia.

$P$. ¿Qué grupo o grupos encabezan la independencia de 1821 , y qué factores influyen para que éstos decidan anexarse a Colombia?

$R$. Bueno, lo que decide anexarse a Colombia es la imposibilidad material de consolidar el estado nacional, y eso tiene que ver con el siglo XVIII, como le decía hace poco. Ahora, ¿qué grupo

\footnotetext{
${ }^{6}$ Este texto puede encontrarse en Justo Arosemena, Panamá y nuestra América, Introducción, selección y notas de Ricaurte Soler, México, UNAM, 1981, (Biblioteca del Estudiante Universitario, núm. 107).
} 
fundamentalmente? La burguesía comercial y la pequeña burguesia y capas medias de las ciudades, que son las que van a ser el sustento, por otra parte, del liberalismo panameño del siglo XIX. La politica y la cultura panameña del siglo XIX están francamente dominadas por el liberalismo y no hay una base social para el conservatismo panameño; no tan fuerte como la hubo en los otros países hispanoamericanos. Esto es muy largo de explicar porque... Pero solamente podría decirles muy rápidamente que en Panamá la Iglesia no fue poderosa económicamente durante la época colonial. También podria decirles que en Panamá no hubo mayorazgo durante la época colonial y que la economía de carácter transitista ha tenido, claro, efectos muy negativos, pero ha tenido también algunos otros aspectos positivos; entre los aspectos positivos está el hecho de que en Panamá nunca se ha asentado una sociedad de carácter señorial por el estilo de la que hubo en otros paises hispanoamericanos. ${ }^{7}$

$P$. ¿Cómo se podría caracterizar la sociedad panameña después de su independencia de España?

$R$. Continúa siendo dominada fundamentalmente por la burguesía comercial y la pequeña burguesía y capas medias de las ciudades; y la bandera de la autonomía fue levantada reiteradamente a través de todo el curso del siglo xIx y eso ustedes lo pueden ver en cronologias, que abundan. $Y$ hay que tener muy presente que después de la Constitución de 1832 de la Nueva Granada, cuando se dieron movimientos centrofederales en la década de los 50, el primer estado federal autónomo que se creó fue el estado de Panamá en el año de 1855, gracias a las gestiones de Justo Arosemena. Y después, cuando la Nueva Granada se convirtió en los Estados Unidos de Colombia, en 1863, con la Constitución de Río Negro, para entonces Panamá fue autónoma y federal. Como tantos otros estados de los Estados Unidos de Colombia, Panamá tuvo entonces un régimen de autonomia política desde 1855 hasta 1885 , son treinta años, cuando se decapitó la Constitución del 63, por Rafael Núñez, y se creó la nueva Constitución centralista de 1886 . Panamá quedó sometida directamente al gobierno de Bogotá y esto naturalmente que trajo muchas contradicciones con los grupos dominantes panameños. En mi concepto, esos grupos dominantes en aquellos momentos eran progresistas, porque lo que tenemos como alternativa era la sociedad señorial colombiana, muy poco compatible como diriamos, la actividad comercial, con el espíritu, digamos, laico y las concepciones antropocéntricas que predominaban en el istmo de Panamá. Esto contrastaba más bien con el profundo catolicismo y las características señoriales de la sociedad colombiana.

P. ¿Qué importancia histórica tienen los movimientos separatistas de $1826,1830,1831$ y 1840 con respecto a la formación de la nación panameña?

$R$. Bueno, todos los historiadores panameños siempre han insistido en que tienen una gran importancia, porque son los antecedentes que legitiman el 3 de noviembre desde el punto de vista interno. Evidentemente que la independencia del 3 de noviembre

\footnotetext{
7 Sobre la independencia de Panamá en 1821, véase de Alfredo Castillero Calvo, "Fundamentos económicos y sociales de la independencia de 1821", en Tareas, Panamá, núm. 1, octubre de 1960.
} 
de 1903 fue una independencia mediatizada por los Estados Unidos, exactamente como la independencia de Cuba, que también fue una independencia mediatizada por los Estados Unidos después de la guerra de liberación, la que quedó como ustedes saben, pues, anulada por la guerra hispano-norteamericana. Pero desde el punto de vista nuestro, desde el punto de vista interno, esas luchas por la autonomía y, eventualmente, incluso por la independencia, legitiman el 3 de noviembre de 1903 . Ahora bien, ahí creo que se mencionó una fecha que hay que revisar y creo que dijiste 1830; esa fecha hay que revisarla, y yo consideraria que leas $T a$ reas, la revista Tareas número 5, donde hay un artículo de Alfredo Castillero Calvo sobre el movimiento de 1830 , donde se señala claramente que ése no fue un movimiento autonomista por el estilo, en todo caso, de los anteriores y posteriores. El movimiento de 1830 fue un movimiento centralista, un movimiento bolivariano dirigido por José Domingo Espinar que tiene características muy muy interesantes porque Espinar tiene sobre todo el apoyo del arrabal de Santa Ana; pero no fue un movimiento autonomista en el sentido tradicional, porque lo que quería Espinar era que Bolivar viniera y en Panamá reconstruyera o reconstituyera la Gran Colombia que estaba desmoronándose. De manera que ésa es una excepción que por lo demás confirma la regla; no fue un movimiento autonomista, por lo menos en el sentido en que fueron los otros movimientos autonomistas, incluso independentistas. De todos estos movimientos, probablemente el más importante fue el de $40-41$, porque durante poco más de un año Panamá fue realmente independiente de la Nueva Granada. ${ }^{8}$

$P$. ¿Qué importancia tiene el interior en la historia de Panamá hacia mediados del siglo XIX?

$R$. La economía de Panamá, hay que recordarlo, siempre ha sido fundamentalmente economia de tránsito, eso le da una fisonomía muy particular; esto tiene aspectos muy negativos y algunos que otros aspectos positivos. El interior ${ }^{9}$ ha sido, diriamos, solidario económicamente de la zona de tránsito, lo que en la historia de la formación de los estados nacionales en Europa constituyó el núcleo a partir del cual se fueron generando, se fue homogeneizando la sociedad civil. El núcleo fueron las ciudades, y eso hasta cierto punto continúa siendo válido para la formación de los estados nacionales en la América Latina; es a partir de las ciudades que se va irradiando toda una red de relaciones económicas y comerciales o de cualquier tipo que van haciendo homogénea la sociedad civil. Entonces, el interior, desde este punto de vista, tiene una importancia secundaria en cuanto a la formación del estado nacional.

${ }^{8}$ Para mayor información sobre el movimiento de 1826 , puede consultarse: Alfredo Castillero Calvo, "El movimiento anseatista de 1826. Primera tentativa autonomista de los istmeños después de su anexión a Colombia", en Tareas, Panamá, núm. 4. mayo, junio de 1960. Para el movimiento autonomista de 1840 , puede consultarse: Ricardo Joaquín Alfaro, Vida del general Tomás Herrera, Panamá, Editorial Universitaria, 1982. Los movimientos señalados también son tratados a nivel general en la obra de Ernesto de Jesús Castillero Reyes, Historia de Panama, Panamá, América, 1955.

"Se denomina "interior" a la región ubicada en la zona centro-oeste de Panamá, cuyas principales actividades son la agricultura y la ganadería. 
$P$. ¿Cuáles son los efectos que produce en la sociedad panameña la construcción del ferrocarril transístmico?

$R$. La construcción del ferrocarril, lo mismo que la construcción, después, del canal francés, lo mismo que después la consitrucción del canal norteamericano, tuvo efectos de, diríamos, de aparente crecimiento; pero la construcción del ferrocarril, el ferrocarril de Panamá, dejó de tener importancia desde 1869, por ahí poco más o menos, cuando se construye el ferrocarril transcontinental de los Estados Unidos. Entonces, estos son los aspectos terriblemente negativos de la economia transitista; una vez que por una coyuntura cualquiera el tránsito deja de ser importante, entonces el país se hunde en un marasmo económico tremendo. De manera que esto que digo para la construcción del ferrocarril, e incluso hasta 1869 poco más o menos, es igualmente aplicable a la construcción del canal francés, a la construcción del canal norteamericano, etcétera. ${ }^{10}$

$P$. ¿Qué intereses se encuentran detrás de los grupos de conservadores y liberales y qué proyectos o perspectivas ofrece cada cuál?

$R$. Bueno, ya les dije que en Panamá el conservatismo no tuvo una base social importante. En Panamá el liberalismo dominó, sin discusión, durante el siglo XIX y gran parte del siglo $\mathrm{XX}$, y ya les dije también las razones. Ahora simplemente les voy a añadir una razón más: en América Hispana, de los grandes conquistadores, o a partir de los grandes conquistadores en la América, se enseñorearon enormes latifundios o mayorazgos, etcétera -y ustedes lo deben saber mejor que yo, en el caso de Cortés con el marquesado del Valle-. Bueno, en Panamá lo medular de su descubrimiento y conquista fue realizado por Pedrarias Dávila; entonces, ¿qué de particular tiene Pedrarias en comparación con los otros conquistadores? Tiene algo muy especial, y es que Pedrarias vino como funcionario de la corona; Pedrarias, que sepamos, no firmó capitulaciones que le iban a dar a él mayorazgos y etcétera, sino que él vino como un funcionario de la corona y entonces no, no derivó de la conquista de Panamá por Pedrarias ningún marquesado, ningún mayorazgo, nada por el estilo. Desde ese punto de vista, comparar el descubrimiento y conquista de Panamá con los otros países hispanoamericanos... Algo muy interesante, hubo nada más un ducado, el ducado de Veragua que se le adjudicó a un familiar de Colón, pero eso fue símbolo, no tuvo absolutamente ninguna importancia y desapareció rápidamente.

$P$. ¿Cuáles fueron los efectos que tuvo la concreción de la idea de Justo Arosemena al crearse el estado federal, con respecto a la afirmación de la nacionalidad panameña?

$R$. Bueno, la verdad es que durante el periodo del estado federal Panamá vivió una profunda anarquia; pero habría que estudiar con cierto detenimiento y eso no está lo suficientemente bien clarificado, hasta dónde esa anarquía no fue inducida por la anarquía que estaba viviendo toda Colombia. Porque se crea el estado federal en el 55, pero recuerden que toda Colombia se convierte en un

\footnotetext{
${ }^{10}$ Los diversos proyectos de construcción de un camino transístmico se encuentran excelentemente tratados por Gerstle Mack, La tierra dividida; historia del canal de Panamá y otros provectos istmicos, Panamá, Universitaria, 1971.
} 
estado federal que lleva el federalismo hasta los últimos extremos, algo realmente increíble, de un democratismo y de un ultrafederalismo que, a veces, digo, parecen cosas increíbles; esa Constitución de Río Negro, por ejemplo, en principio contemplaba la posibilidad de que un estado de la unión colombiana le declarara la guerra a otro estado de la unión colombiana, cosas tan increíbles como ésas. Entonces, cada dos años habia elecciones nacionales, es decir, en toda Colombia, y cada estado tenia su constitución y muchos estados tenían también elecciones cada dos años, como decía un profesor mío: Colombia estaba viviendo en un permanente plebiscito durante todo el tiempo. De manera que esta situación de anarquía generalizada también se proyectó evidentemente sobre Panamá, pero de todas maneras algo quedó y es importante la experiencia, buena o mala, pero la experiencia del autogobierno durante un periodo de 30 años.

$P$. ¿Cuáles fueron las causas por las que Panamá llegó a hacer tan violenta la guerra de los Mil Días?

$R$. Bueno, a esa pregunta he tratado de responder en algunos trabajos mios, y hay que recordar lo siguiente: en Panamá la lucha autonomista, e incluso independentista, se inició prácticamente con el artículo noveno del acta de independencia de 1821. Ahora bien, el liberalismo, que estaba en la oposición en la guerra de los Mil Dias, levantaba todavía la bandera federalista, de manera que para Panamá liberalismo era igual a federalismo y federalismo era igual a autonomia; luchar por el federalismo y por el liberalismo era luchar por la autonomía: ésa es la razón por la cual el liberalismo sobrevivió militarmente en Panamá todavia durante mucho tiempo, cuando el liberalismo habia sido derrotado en otras regiones de Colombia. Por eso es que nosotros decimos, con toda razón, creo yo, que la guerra de los Mil Dias fue el prólogo de la independencia. Desgraciadamente... la guerra de los Mil Dias se clausuró como una... terminó con una derrota liberal. ¿Esto qué significaba? Eso significaba entonces que ya la vía de la autonomía quedaba liquidada, quedaba clausurada. ¿Qué vía quedaba? La vía de la independencia, pero la vía de la independencia mediatizada por el imperialismo.

$P$. ¿Cuál es el tratamiento que ha dado la historiografía colombiana al istmo de Panamá durante el periodo de anexión?

$R$. Durante el periodo de anexión, la historiografía colombiana surgió muy poco de Panamá; posteriormente sí, hay algunos libros y hace algunas décadas, de algunos lustros para acá, que se han ocupado de la independencia de Panamá; pero hay una perspectiva que a mi entender es una perspectiva errónea, porque solamente ven en el caso de Panamá el zarpazo imperialista, no ven... las causas internas de la independencia, no ven las causas endógenas. Y sobre el particular hay libros, incluso hay un libro de un panameño que está en contra de la independencia de Panamá, o que estuvo en contra de la independencia de Panamá, el libro de Oscar Terán que se llama: Del Tratado Herrán-Hay al Tratado Hay-Bunatt-Varilla". "Y hay además otros libros, el de Lemaitre,

1 Del Tratado Herrán-Hay al Tratado Hay-Bunau-Varilla: Panamá, historia critica del atraco yanqui al llamado en Colombia la pérdida de Panamá y en Panamá nuestra independencia de Colombia, Bogotá, C. Valencia, 1979. 
sobre Panamá. ${ }^{12} \mathrm{Y}$ en fin, algunos otros que ahora mismo se me escapan; pero en general la tendencia es a no entender las causas internas de la independencia de Panamá, a no valorar los movimientos autonomistas o simplemente a desconocer los del siglo XIX.

$P$. ¿Y el estado actual de la historiografía panameña sobre el siglo XIX, más o menos cuál podría ser?

$R$. Yo diría que se está trabajando bastante; sobre todo se está trabajando la figura de Arosemena, que es tan importante para nosotros en el siglo XIX. Independientemente de los trabajos míos, hay un trabajo de Nils Castro que introduce una selección escrita y publicada en la Habana que se llama Patria y Federación; la introducción de él se llama: "Justo Arosemena antiyanqui y latinoamericanista", es un trabajo muy interesante y si no lo han leido sería conveniente que lo leyeran. Una de las últimas cosas que yo he escrito sobre Arosemena está publicada en uno de los últimos números de la revista Tareas, pero es también una parte de la introducción a una selección del escritor Arosemena que fue publicada por la Biblioteca Ayacucho, de Caracas, el número 92; y esa selección lleva por título Fundación de la Nacionalidad Panameña.

12 Panamá y su separación de Colombia: una historia que parece novela, prólogo por Abelardo Forero Benavides, Bogotá, Editorial Kelly, Biblioteca Banco Popular, 1971. 